\title{
Swedish HIV Caregivers’ Experiences of Providing Care to HIV-Positive Migrants: A Qualitative Study
}

Manijeh Mehdiyar $^{1 *}$, Rune Andersson ${ }^{1,2}$ and Katarina Hjelm ${ }^{3}$

${ }^{1}$ Department of Infectious Diseases, Institute of Biomedicine, the Sahlgrenska Academy, University of Gothenburg, Sweden

${ }^{2}$ Sahlgrenska University Hospital, Gothenburg, Sweden

${ }^{3}$ Department of Public Health and Caring Sciences, Uppsala University, Sweden

\begin{abstract}
Background: HIV has become a chronic disease, due to the result of advances in HIV treatment in the past two decades. However, the processes shaped by socio-economic factors have been proven to be the main cause of vulnerabilities related to HIV among migrants globally. In spite of the development of effective HIV treatment in the past two decades, there are still many obstacles to delivering the care to different socio-economic and ethnic groups, such as late HIV testing. More knowledge of HIV care providers' experiences is needed in order to support them in their work and create optimal health care for HIV-positive migrants.
\end{abstract}

Objective: The aim of this study was to explore the experiences of HIV caregivers in providing care to HIV-positive migrants.

Methods: A qualitative exploratory design with focus-group interviews for data collection was chosen. The participants were recruited from three infectious disease clinics in Sweden. Five focus-group interviews were conducted. Each focus group comprised three to five nurses and social workers.

Results: The study revealed that the HIV caregivers experienced that their patients suffered from stigma, selfstigma and social marginalisation, which in turn required more resources and support from them. The socio-economic vulnerability of the migrant patients necessitates particular social support from caregivers to these patients, depending on different migration processes that characterise the patients' lives. Further, we found that the contact-tracing the social workers had to perform according to Swedish law could be contradictory to the supportive therapy of the patients.

Conclusion: Our study showed that the stigma and social vulnerability of HIV-positive migrants in different respects call for extra support from the caregivers in order to respond to the needs of HIV-positive migrants through targeted interventions. More resources are needed within the different fields of social support, in order to provide optimal care and support to HIV-positive migrants.

Keywords: HIV; Caregivers; Migrants; Work experience; Focusgroup

\section{Introduction}

HIV has become a chronic disease, due to the result of advances in HIV treatment in the past two decades [1]. However, there are still many obstacles to the effective delivery of HIV-related care, even within the most advanced health-care systems. Late testing, poor access to care and treatment, together with the failure to remain in care, are some of the challenges to the effective delivery of HIV-related care [1]. Late HIV testing is overrepresented among the migrant population in western countries [2]. The influence of perceived HIV stigma varies in relation to the individual's socio-economic status and explains the exposure of vulnerability to stigma [3].

The processes shaped by socio-economic factors have been proven to be the main cause of vulnerabilities related to HIV among migrants globally [4]. It is already known that psychological and social factors have a deep impact on the treatment of HIV infection in Western Europe, as well as in Canada and Australia. For instance, a minority of the HIV-positive patients living in these countries could still have access to care, but they choose not to use the therapy [5].

A previous study by our research group of HIV-positive migrants' encounters with the Swedish health-care system demonstrated that free access to antiviral therapy was necessary but not enough for these patients to feel satisfied with the Swedish health-care system [6]. Existing limitations of access to health care and perceptions of discrimination within the general health-care system were the main reasons for dissatisfaction among them.
A systematic review of qualitative research on worldwide HIV caregivers' experience of HIV testing and counselling revealed that an inclusive management structure and sufficient human and material resources are crucial for caregivers to provide optimal care [7]. The result also showed that optimal care requires time and the ability to apply a patient-centred approach. The patient-centred approach is originally based on the idea of understanding each patient as a unique human being [8] and it is also based on supporting each person's ability and strength through a positive attitude and individual support during the caring process $[9,10]$. There is also a positive association between patient-centred communication and patient satisfaction and health outcomes among HIV-positive patients [11].

Due to the complexity of the disease and its connection with social circumstances, more knowledge of caregivers' experiences of work-

*Corresponding author: Manijeh Mehdiyar, Department of Infectious Diseases, Institute of Biomedicine the Sahlgrenska Academy, University of Gothenburg,10a, Box 7193, SE-40234 Gothenburg, Sweden, Tel: 46722505454 E-mail: manijeh.mehdiyar@gu.se

Received February 13, 2018; Accepted February 20, 2018; Published February 27,2018

Citation: Mehdiyar M, Andersson R, Hjelm K (2018) Swedish HIV Caregivers' Experiences of Providing Care to HIV-Positive Migrants: A Qualitative Study. J AIDS Clin Res 9: 758. doi: 10.4172/2155-6113.1000758

Copyright: (c) 2018 Mehdiyar M, et al. This is an open-access article distributed under the terms of the Creative Commons Attribution License, which permits unrestricted use, distribution, and reproduction in any medium, provided the original author and source are credited. 
ing with HIV-positive patients is crucial for effective treatment. HIV care providers often experience isolation, a lack of natural support and discrimination based on their chosen line of work [12]. A systematic review of barriers to HIV testing, counselling and care in Europe has shown that a greater knowledge of health-care providers' experience and attitudes towards patients is critical in order to improve the effectiveness of HIV care and counselling [13].

To summarise, the existing research illustrates our knowledge of the complexity of the disease and its connection to social circumstances. Among other things, there is, however, a shortage of knowledge of HIV caregivers' experiences of working with HIV-positive patients, not least HIV-positive migrants, which is crucial for effective treatment. The aim of this study was to explore the experiences of HIV caregivers in providing care to HIV-positive migrants.

\section{Theoretical framework}

Care and caring processes have always existed in human history. The existence of others has been confirmed in care and through caring process as something most natural and human. The caring process represents a pathway to the realisation and preservation of the idea of care and its origin as an expression of true humanity and something that confirms the caregiver as a human being. Regardless of whether it is to satisfy human beings' most basic requests and needs or to carry out a medical-technical task, the action of care can be permeated by the innermost essence of humanity [14].

In recent decades, person-centred care has been developed as a care philosophy which is based on humanistic ideas that all people are unique, worthy, competent and equal [15]. Person-centred care emphasises that every human being has the potential and resources to develop and change his or her life. Caring processes should therefore focus on supporting each person's ability and strength by positive attitudes and individual support during the caring process $[9,10]$.

\section{Materials and Methods}

In order to describe caregivers' experiences of working with HIVpositive migrants, a qualitative exploratory design with focus-group interviews was chosen as the data collection method. Focus-group interviews are based on the dynamic of group interaction and support the participants in remembering events, deepening sharing experiences and generating rich data, more than the answers to any number of single interviews [16].

\section{Participants}

The participants were recruited from three infectious disease clinics in western Sweden. Permission to contact and recruit the participants was obtained from the heads of the departments. All staff members who worked with HIV-positive migrants at the three studied clinics were invited to participate, but only nurses and social workers agreed and physicians declined, citing a lack of time. Ten nurses and four social workers agreed to participate. The participants were all female, had a university degree in nursing science or social work and had been working at the clinics for between two and 22 years.

\section{Data collection}

The focus-group interviews were performed in 2013-2014. An interview guide with open questions was developed, based on the literature and the experts. It provided a framework for the discussion between the authors at the beginning and continued with followup and in-depth questions. The guiding questions were designed as follows: 1 . How do you perceive your work with HIV-positive migrants? - with regard to HIV-positive migrants' needs?- with regard to your opportunities to support HIV-positive migrants' needs?2. How do you perceive the opportunities and challenges in working with HIV-positive migrants? - at an individual level? -at a structural level?

Focus-group interviews were conducted with four groups consisting of 14 caregivers. Each focus group comprised between three and five participants. All but one was interviewed twice, because there was a need for additional information from one group. The first interview was conducted as a pilot. At some clinics, the focus-group interviews consisted of both social workers and nurses, while in others the groups consisted of nurses and social workers separately. In both groups, the group dynamic was optimal. The interviews were audio-taped and transcribed verbatim by the first author.

The location of the focus-group interviews was chosen at the infectious disease clinics, according to what suited the participants, in secluded rooms. The interviews lasted approximately one hour and were moderated by the first author, who is a sociologist with experience of working with HIV prevention. Moreover, according to the aim of the study, during the focus-group interviews, the moderator decided where more information was needed and also when the discussions should move on [16].

The group interaction during the focus-group interviews was perceived as dynamic and optimal, due to the constructive interview atmosphere and the engaged and verbal nurses and social workers.

\section{Data analysis}

The focus-group interviews were analysed according to the method described by Krueger \& Casey, based on a detailed analysis of the text and content interaction of the data. In order to give a comprehensive picture of the data, the interview text was read as a whole several times in its context and related to the aim of the study. The analysis of the content of the data proceeded by identifying and bringing together the meaning units according to their differences and similarities. The next step was to name/label each of these meaning units with a code and then continue by sorting the codes into subcategories according to their relationships. Subcategories with similar contents were sorted into categories and were named according to their content. The analysis of data proceeded simultaneously with data collection and continued until no new information was added to the data analysis [16]. Comparisons were made throughout the entire process of data analysis between subcategories and the text as a whole.

\section{Ethical considerations}

Ethical approval for the study was given by the Regional Ethical Review Board in Gothenburg in 2012, registration number 681-11, T275-12. The participants were informed about the aim of study and the confidentiality and anonymity of the participant were guaranteed [17]. Verbal informed consent was obtained from the participants before proceeding with interviews. The tape recorder and the transcribed interviews were kept in a locked, protected place to which only the first author had access.

\section{Results}

The results of the study revealed three different categories and their subcategories see Table 1. The first category was Caregivers' general challenges with the following subcategories: Lacking time for communication and support and Stigma/self-stigma. The second category was the challenge of the patients' migration status and the subcategories 


\begin{tabular}{|l|l|l|}
\hline \multicolumn{1}{|c|}{ Category } & \multicolumn{1}{|c|}{ Sub-category } \\
\hline 1. Caregivers' general challenge & $\begin{array}{l}\text { a) Lacking time for communication and support } \\
\text { b) Stigma/self-stigma }\end{array}$ \\
\hline 2. The challenge dealing with the patients' migrant status & $\begin{array}{l}\text { a) Lack of information about the Swedish welfare system } \\
\text { b) Vulnerability due to lack of patient associations and patient networks } \\
\text { c) Socio-economic vulnerability of HIV-positive migrants } \\
\text { d. Social workers' perceived double roles }\end{array}$ \\
\hline
\end{tabular}

Table 1: Categories and sub-categories.

were: Lack of information about the Swedish health-care system, vulnerability due to lack of patient associations and patient networks, Socio-economic vulnerability of HIV-positive migrants and Gender and sexuality. The third category was Social workers' double roles.

\section{Caregivers' general challenges}

This category revealed the challenges caregivers face in their work with HIV patients, regardless of their origin. The category is expressed through two sub-categories: "Lacking time for communication and support" and "Stigma and self-stigma".

Lacking time for communication and support: The caregivers and the nurses in particular experienced that they had insufficient time for more communication and discussion with their patients according to the patients' individual need for conversation and communication about their disease.

"On the surface, there is no problem, but many of the patients are still terrified and don't know so much about the disease, the uneducated ones, you know. They have no knowledge of the disease and we give them knowledge of medicines and the fact that they are not going to die. But they don't really know about the disease and what will happen and how the medicine works."

"Now we can better explain something we said in the beginning. I think we take very good care of the patients, but we don't have time to sit without interruption with them... we don't have time to do the interviews. We don't have time to sit and discuss, because we know that we only have half an hour and then the next patient will arrive and we can't maintain the amount of space at any time with the inclusion of this patient, because we have so many other patients as well."

Stigma and self-stigma: The caregivers experienced that the stigma linked to HIV was divided into self-stigma and stigma. With stigma, they described society's attitudes towards HIV-positive individuals in general, which has in turn caused self-stigma among some patients. A nurse at one of the infectious disease clinics talked about her experience of one patient's self-stigma.

"We had an HIV-positive patient from another area and then we got a new secretary who this patient happened to know and, when the patient saw the new secretary for the first time, he panicked, totally panicked. And then I said that she (the secretary) had a duty of confidentiality like any other member of staff at the clinic, but he still totally panicked. And then he chose to move to another clinic instead, in order not to be recognised."

\section{The challenge of the patients' migration status}

Caregivers experienced different challenges in supporting HIVpositive persons with migration status in their everyday life. In their experience of working with them, the participants said that these patients were exposed to higher degrees of vulnerability in different ways and were in extra need of social support, in addition to medical treatment.
Migration status included a wide range of situations, from asylum seekers and undocumented migrants to migrants with a residence permit and citizenship. They had also lived in Sweden for a short or a long time. The data analysis generated four subcategories for this category: "Lack of information about the Swedish welfare system", "Vulnerability due to lack of patient associations and patient networks", "Socio-economic vulnerability of HIV-positive migrants" and "Gender and sexuality".

Lack of information about the Swedish welfare system: The caregivers stated that access to information about the Swedish healthcare system and its functions, as well as the right to know about the Swedish welfare system and its complexity, were essential for migrant patients to obtain access to these rights.

"Because, after all, it happens that they do not know about their rights for various reasons. People have many rights in Sweden and people need to recognise them to be able to obtain or access them."

Vulnerability due to a lack of patient associations and patient networks: HIV-positive migrants are not active in the patient associations in the same way as HIV-positive native Swedes, according to the participants. Caregivers experience that the lack of access to a network has caused more isolation among HIV-positive migrants, which has, in turn, deprived them of information and support.

"Our social worker tried to get Thai women together to create a network, but none of these women wanted to, because they did not want to meet someone who has HIV. Because no one wants to know if they have HIV and they are afraid of meeting someone that they know. If you think about the Rheumatism Association and all the other patient associations that work strongly together, in this context, I experience that everyone wants to keep it to themselves." (P7)

Socio-economic vulnerability: The social and economic vulnerability of the migrant patients was dependent on their respective status in the asylum-seeking process or their migration status and the different stages of the exile processes, caused by the shortage of access to knowledge, wealth, power and social resources. The social and economic status of HIV-positive migrants varied considerably and this led to various degrees of challenge for the caregivers when it came to providing them with support. In this respect, two social workers described their experience in a dynamic interaction during the focusgroup interviews about giving support to an HIV-positive asylum seeker.

"And there will be a lot of contact with the authorities and immigration office, lawyers and so on and, even though weal ways try, weal ways try, weal ways try within our framework and a bit more for contact with the authorities and help the patients to handle their anxiety and powerlessness. And we have had patients with children."

"Yes, we help patients by writing certificates, by reminding them about things they have forgotten. So we are actually the support person in the asylum process. We have discussions with one lawyer or another 
and sometimes we also help the lawyers with their work. We tell them how to write, we help them with the interpreter and so on."

Gender and sexuality: As HIV is so closely connected to sexuality, information and communication about sexual and reproductive health between caregivers and HIV-positive patients are central. Caregivers experienced difficulty communicating sexuality with the migrant women at the clinic. Furthermore, caregivers experienced that migrant women were often quiet and refused to open up and talk about their sexuality in relation to HIV.

"It is very difficult to start a discussion about sexuality with them. If you ask the ones that are single or have had a relationship that is over and you ask if they have met anew man, some of them just laugh and say that they are not interested in a new man."

\section{Social workers' double role}

The third category describes the different roles social workers played at the infectious disease clinics which could be contradictory. The social workers' task at the clinic was to trace the HIV patients' contacts, but they were also supposed to provide the patients with supportive conversation therapy. These two different roles opposed each other and made it difficult to provide the patients with optimal therapy.

"In our profession, we have dual roles. We are used to having dual roles. We exercise public authority, trace contacts and provide support."

\section{Discussion}

The main finding in the study was the general challenge experienced by care givers due to the stigma and self-stigma to which HIV patients perceived they were exposed and also caregivers' experiences of challenges associated with the patients' migrant status. The need for resources for optimal support and care for HIV patients who suffer from stigma, self-stigma and social marginalisation has already been shown to be significant [3]. Our previous study of HIV-positive migrants' experience of the health-care system in Sweden showed that these patients needed more time for communication with their caregivers at the clinics. The patients wanted more time to communicate updated information on HIV and their medication with doctors [6].

HIV is very closely connected to social stigma. However, the impact of stigma on the HIV-positive individual's life varies depending on the individual's social context [3]. Further, empowerment through communication has been shown to play a significant role in the treatment of vulnerable patients [18]. Communication is a key part of the meeting between caregivers and patients, according to the 'personcentred care' approach. It is considered to be the main resource for the patient to have an opportunity to be involved in health care and obtain information about treatment. However, communication requires time, resources and individualised approaches in the contact with patients. The additional resources for communication in 'person-centred care' will create more value for care and reduce societal costs [19].

The social workers' perceived double roles were another finding in this study. It showed that there was a conflict between the social workers' task of providing psychosocial support and therapy to HIVpositive patients and tracing contacts according to the "Swedish Disease Act" [20]. In contact-tracing, the HIV-positive patients have to answer the questions the social workers ask about their sexual partners and this in turn impacts the idea of counselling based on mutual trust and openness. The World Health Organisation (WHO) emphasises the importance of access to counselling and social support for HIV-positive patients, as HIV affects every dimension of a person's life: physical, psychological, social and spiritual [21]. A Swedish study showed a positive correlation between counselling, networking and openness about HIV status among HIV patients with an African background in Sweden [22].

Our study further showed that the socio-economic vulnerability of the migrant patients necessitates particular social support from caregivers to these patients, depending on different migration processes that characterise the patients' lives. Due to the European Parliament's resolution [23] on "Reducing health inequalities in the EU", the member states are urged to adopt a holistic focus on social support and care in order to reduce health inequalities.

The participants in this study were limited to the nurses and social workers who work with HIV patients at the infectious disease clinics. The views and experiences of the physicians who work there is therefore not included in this study, but they need to be studied in more detail. The results of the qualitative studies are considered to be limited in their general is ability. In this study, the aim was to explore the knowledge of care givers' experiences of the care given to HIV patients at the infectious disease clinics, instead of generating data that can be generalised to the whole population. Qualitative data can be transferred to other similar groups if they are carefully described, collected and analysed [24]. The strength of this study, like exploratory qualitative studies, is its applicable access to the new knowledge within the field of caregivers' experience of the care given to HIV-positive migrants, as there has been a shortage of knowledge in this research area.

\section{Conclusion}

Our findings in this study were that HIV care givers experienced the need for more time for communicating with and supporting HIV migrants due to the stigma and self-stigma to which the migrant patients are exposed. Furthermore, the socio-economic vulnerability of migrant patients necessitates more resources for optimal care.

Even though more studies need to be conducted in order to improve our knowledge within the field of HIV caregivers, the results of this study should be taken into consideration by the decision-makers responsible for health-care systems. More resources are needed within the different fields of social support, in order to provide optimal care and support to HIV-positive migrants.

\section{Acknowledgement}

We thank Dr Lene Povlsen for help with the design of the study and for application to ethics committee.

\section{Funding}

Research Fund "Agreement concerning research and education of doctors" at VästraGötaland Region, Sweden

\section{References}

1. Deeks SG, Lewin SR, Havlir DV (2013) The end of AIDS: HIV infection as a chronic disease. Lancet 382: 1525-1533.

2. Del Amo J, Perez-Cachafeiro S, Hernando V, González C, Jarrín E, et al (2010) Migrant health: Epidemiology of HIV and AIDS in migrant communities and ethnic minorities in EU/EEA countries.

3. Block RG (2009) Is it just me? Experiences of HIV-related stigma. J HIVIAIDS Soc Serv 8: 1-19.

4. Hirsch JS (2014) Labor migration, externalities and ethics: theorizing the mesolevel determinants of HIV vulnerability. Soc Sci Med 100: 38-45.

5. Newman CE, Mao L, PerssonA, Holt M (2015) Not until I'm absolutely half-dead and have to: Accounting for non-use of antiretroviral therapy in semi-structured interviews with people living with HIV in Australia. AIDS Patient Care STDS 29: $267-278$. 
Citation: Mehdiyar M, Andersson R, Hjelm K (2018) Swedish HIV Caregivers' Experiences of Providing Care to HIV-Positive Migrants: A Qualitative Study. J AIDS Clin Res 9: 758. doi: 10.4172/2155-6113.1000758

Page 5 of 5

6. Mehdiyar M, Andersson R, Hjelm K, Povlsen L (2016) HIV-positive migrants' encounters with the Swedish health care system. Glob Health Action 9: 31753.

7. Evans C, Nalubega S, Mc Luskey J, Darlington N, Croston M, et al. (2016) The views and experiences of nurses and midwives in the provision and management of provider-initiated HIV testing and counseling: a systematic review of qualitative evidence. JBI Database System Rev Implement Rep 13: 130-286.

8. Balint E (1969) The possibilities of patient-centred medicine. J Roy Coll Gen Pract 17: 269-276.

9. Morgan S, Yoder LH (2012) A concept analysis of person-centered care. J Holist Nurs 30: 6-15.

10. Slater L (2006) Person-centeredness: A concept analysis. Contemporary Nurse 23: $135-144$

11. Beach MC, Keruly J, Moore RD (2006) Is the quality of the patient-provider relationship associated with better adherence and health outcomes for patients with HIV? J Gen Intern Med 21: 661-665.

12. Rowan D, Randall E, Johnson H (2015) Deconstructing Burnout in HIV. J HIV AIDS Soc Serv 14: 58-73.

13. Deblonde J, De Koker P, Hamers FF, Fontaine J, Luchters S, et al. (2010) Barriers to HIV testing in Europe: A systematic review. Eur J Public Health 20: 422-432.

14. Eriksson K (1995) Vårdprocessen. Vårdserie Almqvist \&Wiksell. Liber Utbildning $A B$.
15. Mc Cormack B, Mc Cance T (2010) Person-centred nursing: Theory and practice. Wiley \& Blackwell. United Kingdom.

16. Krueger RA, Casey M (2015) Focus Groups: A practical guide for applied research. Thousand Oak, Sage publications, California.

17. World Medical Association Declaration of Helsinki (2013) Ethical principles for medical research involving human subjects. JAMA 20: 2191-2194.

18. Jotterand F, Amodio A, Elger BS (2016) Patient education as empowerment and self-rebiasing. Med Health Care Philos 19: 553-561.

19. Bolster D, Manias E (2010) Person-centred interactions between nurses and patients during medication activities in an acute hospital setting: Qualitative observation and interview study. Int J Nurs Stud 47: 154-165.

20. http://www.riksdagen.se/sv/DokumentLagar/Lagar/Svenskforfattningssamling/ Smittskyddsforordning-200425_sfs-2004-255/?bet_2004:255

21. World Health Organisation (2016) Global health sector strategy on HIV 2016 2021: Towards ending AIDS. WHO

22. Åsander AS, Belfrage E, Pehrson PO, Lindstein T, Björkman A (2004) HIVinfected African families living in Stockholm/Sweden: Their social network, leve of disclosure and knowledge about HIV. Int J Soc Welf 13: 77-88.

23. http://www.europarl.europa.eu/sides/getDoc.do?type=REPORT\&reference=A72011-0032\&language $=\mathrm{EN}$

24. Patton MQ (2015) Qualitative research \& evaluation methods. Sage publication, London. 